Palavras chave:

Conservação

Copernicia prunifera

Conhecimento tradicional

Extrativismo

Recursos naturais

Histórico:

Recebido 04/10/2013

Aceito 15/1 I/2015

Keywords:

Conservation

Copernicia prunifera

Traditional knowledge

Extraction

Natural resources

Correspondência: rodrigofsousa72@yahoo.com.br
Rodrigo Ferreira de Sousa', Richeliel Albert Rodrigues Silva', Talita Geovanna Fernandes Rocha', José Augusto da Silva Santana', Fábio de Almeida Vieira'

\title{
ETNOECOLOGIA E ETNOBOTÂNICA DA PALMEIRA CARNAÚBA NO SEMIÁRIDO BRASILEIRO
}

RESUMO: O objetivo do presente trabalho foi investigar aspectos etnoecológicos e etnobotânicos da carnaúba (Copernicia prunifera (Miller) H. E. Moore, Arecaceae) em uma comunidade extrativista do município de Ipanguaçu, estado do Rio Grande do Norte. Foram entrevistados moradores considerados informantes-chaves, utilizando a técnica da indução não específica, turnê guiada e observação direta para confirmar as informações obtidas. Segundo a maioria dos moradores do Assentamento Pedro Ezequiel de Araújo, o carnaubal da região é uma formação vegetal natural. Na investigação etnoecológica, $73 \%$ dos informantes relataram a ocorrência de "um tipo diferente de carnaúba", conhecida como "carnaúba branca", fenotipicamente distinta da "carnaúba comum" por apresentar estipe claro, frutos menores e ausência de espinhos no pecíolo, além de ser rara no local de estudo. Grande parte dos informantes observam os processos fenológicos da carnaúba, sendo condizentes ao afirmar que a espécie possui dispersão quiropterocórica. $\mathrm{Na}$ etnobotânica, o pó cerífero foi citado por todos como o produto mais importante extraído da carnaúba e a folha a parte mais usada, seguida dos frutos, caule e raiz. Foram relatadas ainda as divisões de trabalho na extração do pó da carnaúba. Os resultados desta pesquisa irão contribuir para difundir os conhecimentos etnobotânicos e etnoecológicos da carnaúba, subsidiando estratégias de manejo e conservação das populações naturais.

\section{ETHNOECOLOGY AND ETHNOBOTANY OF THE PALM CARNAUBA WAX IN BRAZILIAN SEMI-ARID}

ABSTRACT: The aim of this study was to investigate aspects of ethnoecological and ethnobotanical of carnauba wax (Copernicia prunifera (Miller) H. E. Moore, Arecaceae) in an extractive community of municipality of Ipanguaçu, Rio Grande do Norte state. We interviewed key informants, using the technique of inducing nonspecific, guided tour and direct observation to confirm the data. According to most residents of Pedro Ezequiel Araújo community, the area of carnauba wax in the region is natural. In the research ethnoecological, $73 \%$ of informants reported the occurrence of "a different kind of carnauba", known as "white carnauba" phenotypically distinct from the "common carnauba wax" by presenting clear stipe, smaller fruits and absence of spines on the petiole, and is rare at the study site. Much of the informants observed phenological phases of carnauba wax, being consistent in stating that the species has fruits dispersed by bats. In ethnobotany, powder wax was cited by all as the most important product extracted from leaves of carnauba and the most used, followed by fruit, stem and root. Were still reported the division of work in the extraction of powder wax from the carnauba. The results of this research will contribute to knowledge of ethnobotanical and ethnoecological carnauba, supporting strategies for management and conservation of natural populations.

Universidade Federal do Rio Grande do Norte - Macaíba, Rio Grande do Norte, Brasil 


\section{INTRODUÇÃO}

A carnaúba (Copernicia prunifera (Miller) H. E. Moore) é uma palmeira nativa do nordeste brasileiro, com maior ocorrência nos Estados do Ceará, Piauí e Rio Grande do Norte. O termo "carnaúba" é derivado da língua indígena tupi e significa "árvore-que-arranha”. A espécie é conhecida ainda como "árvore da vida", pois oferece uma infinidade de usos econômicos (GOMES et al., 2009). Sua principal riqueza está na cera que recobre as folhas, principalmente as mais jovens, tornando-a internacionalmente conhecida como "carnauba wax".

O extrativismo de produtos florestais não madeireiros, como ceras e folhas, tem sido considerado uma alternativa para a conservação da biodiversidade, ajudando a proteger as áreas naturais contra usos mais destrutivos da terra, como o desmatamento e a agropecuária (WADT et al., 2005). Além disso, contribui para a melhoria da qualidade de vida de muitas comunidades rurais, que passam a incrementar sua renda com a venda dos produtos coletados, sendo que a importância desta atividade é ainda maior nas comunidades mais carentes (TICKTIN, 2004).

Nesse contexto, o manejo racional dos produtos oriundos da C. prunifera está diretamente relacionado à conservação dos ambientes de ocorrência da espécie. No Estado do Rio Grande do Norte, a $C$. prunifera ocorre com maior frequência nos vales do Rio Açu, onde são encontrados extensos carnaubais. Esse rio é responsável pela maior bacia hidrográfica do estado, onde são encontrados I. I I 2 açudes, numa superfície de 17.500 km², que equivale a $32,8 \%$ do território estadual. Apesar dessa importância, os graves danos provocados por constantes desmatamentos, assoreamento, incidência de agrotóxicos, resíduos tóxicos, lixo urbano, garimpo e outros impactos têm gerado reflexos negativos no ambiente da região. Adicionalmente, vários municípios que compõem a bacia hidrográfica do Rio Açu estão sujeitos à desertificação (MMA, 2005). Devido a isso, essas áreas de ocorrência natural da $C$. prunifera merecem ações urgentes de conservação, que podem ser estruturadas com base na caracterização do conhecimento local e formas de usos da planta pelas comunidades extrativistas.

A etnoecologia é frequentemente usada para designar os estudos que se referem à interação entre uma população humana local e seu ambiente natural (CASTANEDA; STEPP, 2007). Já a etnobotânica é o estudo contextualizado do uso das plantas pelas populações tradicionais (LINS NETO et al., 20I0).
Conforme relata Albuquerque e Andrade (2002), a estrutura das comunidades vegetais é geralmente afetada em diferentes aspectos pelos extrativistas. Sendo assim, é fundamental que seja considerado o conhecimento tradicional das populações tradicionais e os níveis de coleta praticados para então desenvolver práticas sustentáveis de manejo.

objetivo do presente trabalho foi investigar aspectos etnoecológicos e etnobotânicos da carnaúba C. prunifera em uma comunidade extrativista do estado do Rio Grande do Norte, assim como investigar aspectos relacionados às práticas laborais dos moradores, servindo de subsídio para elaboração de estratégias de conservação da espécie.

\section{MATERIAL E MÉTODOS}

\section{Local de estudo}

O estudo foi realizado na Agrovila Picada, Assentamento Pedro Ezequiel de Araújo (APEA), município de Ipanguaçu ( $R N)$, distante aproximadamente $214 \mathrm{~km}$ da capital Natal/RN. O local está inserido na microrregião do Vale do Açu, nas coordenadas $05^{\circ} 3 I^{\prime} 47^{\prime} \mathrm{S}, 36^{\circ} 48^{\prime} \mathrm{I} 8^{\prime \prime} \mathrm{W}$ e altitude de $16 \mathrm{~m}$, em região semiárida. $O$ clima do local, segundo a classificação de Köeppen, é Bswh (Clima Quente de Caatinga), ou seja, seco, muito quente e com estação chuvosa de março a abril, com variações de $1,4 \mathrm{~mm}$ a 1.627 , I mm e média de precipitação anual de 585,8 $\mathrm{mm}$. A temperatura média anual é de $28,1^{\circ} \mathrm{C}$ e umidade relativa média anual de $70 \%$ (COSTA et al., 2010).

Essa área foi escolhida mediante a observação da existência de extensa área de carnaubal e utilização humana constante dos recursos oferecidos pela espécie. A Agrovila Picada abriga 59 famílias que trabalham de forma assalariada no extrativismo da $C$. prunifera, sendo a maioria colonos, assentados da reforma agrária. Os carnaubais ocupam uma área de aproximadamente 600 hectares no assentamento, com distribuição ao longo da Lagoa de Ponta Grande.

\section{Coleta de dados etnoecológicos e etnobotânicos}

Foram entrevistadas II pessoas da comunidade (nove homens e duas mulheres), consideradas informantes-chaves por demonstrarem conhecimentos adquiridos localmente a partir da observação, do uso ou da exploração da C. prunifera. A maioria dos entrevistados foi incluída na amostra quando, no ato da entrevista, o 
primeiro entrevistado citava ou indicava outras pessoas que detinham maior conhecimento sobre a $C$. prunifera. As entrevistas ocorreram ao longo do ano de 2012. Para cada entrevistado foram explicados os propósitos do estudo, sendo solicitadas as Anuências Prévias, por meio do Termo de Consentimento Livre e Esclarecido, para a realização das entrevistas e, em seguida, feitas as perguntas semiestruturadas, que abordaram questões socioeconômicas (sexo, idade, escolaridade e profissão) e questões relacionadas à sua convivência e envolvimento com exploração da $C$. prunifera.

A etnoecologia foi investigada com base em perguntas sobre a biologia vegetativa e reprodutiva da espécie, abordando questões relacionadas, por exemplo, à floração, frutificação e dispersão dos frutos. O estudo etnobotânico abrangeu os tipos de uso popular da espécie (folhas, raízes, frutos, estipe, etc.), assim como aspectos econômicos da exploração e comercialização da $C$. prunifera, visando identificar as utilidades e valor econômico dos derivados da mesma.

Após as entrevistas, as atividades tiveram como base também na metodologia participativa (THIOLLENT; SILVA, 2007), que permite a contínua troca de saberes na dimensão ambiental, difusão de conhecimento e tecnologia, gestão e organização da produção/comercialização da C. prunifera. Desse modo, realizou-se a técnica de indução não específica, sugerida por Brewer (2002) para subsidiar as entrevistas anteriores, visando recordar ou acrescentar outros elementos de interesse na investigação. Por último, realizou-se a técnica da observação direta para confirmar as informações obtidas e turnê-guiada (ALBUQUERQUE et al., 20I0).

\section{RESULTADOS E DISCUSSÃO}

\section{Dados socioeconômicos}

A maioria dos informantes da Agrovila Picada (54\%) apresentou idade compreendida entre 30 e 50 anos, $27 \%$ entre 50 e 70 anos e $18 \%$ com até 30 anos. Em relação ao grau de escolaridade, $36 \%$ são analfabetos, $54 \%$ possuem ensino fundamental e $9 \%$ possui ensino médio completo.

A comunidade é predominantemente formada por agricultores ( $81 \%$ dos entrevistados), sendo a agricultura de subsistência o modelo de produção adotado pelos informantes, $9 \%$ são servidores públicos e $10 \%$ são donas de casa.

\section{Dados etnoecológicos}

Segundo os entrevistados, a população de C. prunifera existe na região do Assentamento Pedro Ezequiel de Araújo há mais de 70 anos (81\% dos informantes). Dois informantes não souberam informar com precisão o tempo de existência do carnaubal.

Todos os informantes afirmaram que o carnaubal originou-se de forma natural, ou seja, não houve a interferência humana no surgimento de indivíduos de C. prunifera naquela localidade, sendo caracterizado pelos moradores como "campo" (91\%), o lugar de maior frequência de plantas de $C$. prunifera, seguido por “beira de estrada" (9\%). Segundo D’Alva (2004), a C. prunifera tem distribuição geográfica nos vales dos rios nordestinos, especialmente no meio-norte e nas maiores latitudes do sertão. A espécie ocorre em ambientes com solos argilosos e em aluviões, onde há maior saturação hídrica e elevados teores de salinidade (HOLANDA et al., 20I I). Estas áreas podem permanecer inundadas por alguns meses do ano e, posteriormente, chegam a ser submetidas ao estresse hídrico nos períodos mais secos. A ocorrência periódica da inundação nos carnaubais dos vales dos rios indica que a espécie deva apresentar adaptações para suportar a diminuição do oxigênio no solo (ARRUDA; CALBO, 2004).

Quando perguntado se existia variabilidade fenotípica na espécie, os moradores afirmaram existir "dois tipos" (73\%), chamadas de carnaúba comum e carnaúba branca, sendo diferenciadas pela presença de espinhos no pecíolo na carnaúba comum e ausência dessa estrutura na carnaúba branca (Figura I).

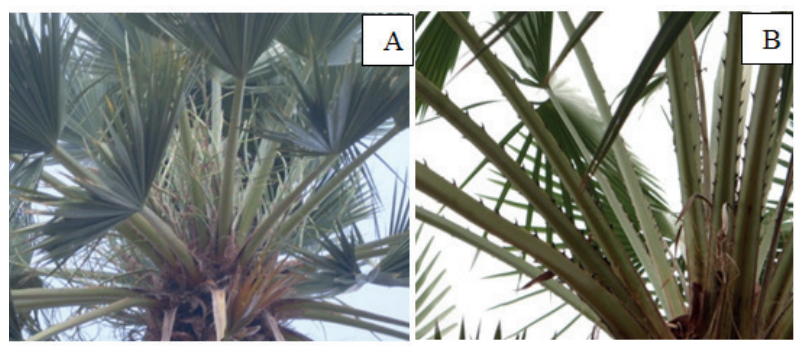

Figura I Carnaúba branca, sem espinhos no pecíolo (A) e carnaúba comum, com espinhos no pecíolo (B). Ipanguaçu, Rio Grande do Norte (RN).

Figure I Carnauba without thorns on petiole (A) and carnauba common with thorns in the petiole (B). Ipanguaçu, Rio Grande do Norte (RN).

Outra diferença marcante entre as duas, relatada pelos informantes, são variações no tamanho dos frutos e enfolhamento apical, onde, a carnaúba branca apresenta frutos menores e mais enfolhamentos 
apicais (dois) em relação à carnaúba comum. Além disso, a carnaúba branca tem suas raízes utilizadas na medicina popular, apresentando característica anti-inflamatória (I8\% dos informantes). Por ser rara na região de estudo (proporção aproximada de I:5.000), alguns informantes (27\%), disseram não conhecer variações fenotípicas da espécie, ou seja, não conhecem a carnaúba branca. Queiroga et al. (20l3), em seu estudo com carnaubeira no nordeste, relatam a existência da carnaúba branca, possuindo como principais características o uso medicinal das raízes, que são mais claras que a comum, além de ser rara na região e não utilizada para extrair o pó cerífero. Entretanto, atualmente são consideradas empiricamente variedades de $C$. prunifera, cuja identificação taxonômica ainda não constitui um caráter definido (QUEIROGA et al., 20I3).

Os processos fenológicos, como floração e frutificação da C. prunifera são observados por grande parte dos moradores $(8 \mathrm{I}, 8 \mathrm{I} \%)$, porém, existem controvérsias em relação aos meses do ano em que isso acontece. Dois informantes disseram que o período de floração começa em agosto e estende-se até setembro. Entretanto, a maioria (nove informantes) afirmou que de outubro a novembro ocorre o período de floração e a frutificação prolonga-se até fevereiro, sendo a dispersão dos frutos feita por morcegos, dispersão quiropterocórica. D'Alva (2004), em seu trabalho de etnobotânica da C. prunifera no estado do Ceará, afirma que o aparecimento dos frutos de carnaúba ocorre entre os meses de novembro a março. Estudos em andamento sobre a fenologia da espécie em uma população remanescente em Macaíba, Rio Grande do Norte, constatou que a floração ocorre entre os meses de outubro a novembro e a frutificação estende-se até o mês março (T.G.F. ROCHA, dados não publicados).

\section{Dados etnobotânicos}

As citações de usos foram divididas em dois grupos distintos, sendo eles: uso madeireiro (construção, tecnologia para a fabricação de cabos para ferramentas, colher, móveis, e produção de energia) e uso não madeireiro (medicinal, artesanato, extração do pó e alimento), $13 \%$ e $87 \%$ respectivamente.

Esses dados mostram significativa predominância dos usos não madeireiros em relação aos usos madeireiros, possivelmente, por se tratar de uma espécie que não possui madeira de alta qualidade quando comparada a tantas outras espécies encontradas no semiárido, como o angico (Anadenanthera colubrina (Vell.) Brenan) e a aroeira (Myracrodruon urudeuva Allemão).

Dados do presente trabalho foram comparados com outros que estudaram a etnobiologia de diferentes palmeiras, a fim de obter mais informações sobre a utilização dos representantes da família Arecaeae em diferentes regiões do país (Tabela I).

Tabela I Comparação entre os dados etnobotânicos do presente estudo com outros trabalhos de palmeiras em diferentes estados do Brasil. Table I Comparison between the ethnobotanical data of this study with other studies of palm trees, in different states of Brazil.

\begin{tabular}{|c|c|c|c|c|c|}
\hline Nome científico & Nome vulgar & Partes Usadas & Utilidade & Local de estudo & Autor \\
\hline $\begin{array}{l}\text { Copernicia prunifera } \\
\text { (Mill) H. E. Moore }\end{array}$ & Carnaúba & $\begin{array}{l}\text { Caule, Cera, Folha, } \\
\text { Fruto, Raiz }\end{array}$ & $\begin{array}{l}\text { Alimentação, Artesanato, } \\
\text { Construção, Medicinal }\end{array}$ & Ipanguaçu - RN & Presente estudo \\
\hline $\begin{array}{l}\text { Astrocaryum vulgare } \\
\text { Mart }\end{array}$ & Tucumã & Folha, Fruto & Alimentação, Artesanato & Bragança - PA & $\begin{array}{l}\text { Rocha \& Silva } \\
(2005)\end{array}$ \\
\hline $\begin{array}{l}\text { Copernicia prunifera } \\
\text { (Mill) H. E. Moore }\end{array}$ & Carnaúba & $\begin{array}{l}\text { Caule, Cera, Folha, } \\
\text { Fruto, Raiz }\end{array}$ & $\begin{array}{l}\text { Alimentação, Artesanato, } \\
\text { Construção, Medicinal }\end{array}$ & Fortaleza - CE & D'Alva (2004) \\
\hline Euterpe edulis Mart. & Juçara & $\begin{array}{l}\text { Caule, Folha, } \\
\text { Fruto, Palmito }\end{array}$ & $\begin{array}{l}\text { Alimentação, Artesanato, } \\
\text { Construção, Ritualístico }\end{array}$ & Ubatuba - SP & $\begin{array}{l}\text { Silva \& Fisch } \\
(20 \mid 2)\end{array}$ \\
\hline $\begin{array}{l}\text { Euterpe oleracea } \\
\text { Mart. }\end{array}$ & Açaí & $\begin{array}{l}\text { Caule, Fruto, } \\
\text { Palmito, Raiz }\end{array}$ & $\begin{array}{l}\text { Alimentação, construção, } \\
\text { Medicinal }\end{array}$ & Bragança - PA & $\begin{array}{l}\text { Rocha \& Silva } \\
(2005)\end{array}$ \\
\hline Mauritia flexuosa L. f. & Buriti & Folha, Fruto & Artesanal & Bragança - PA & $\begin{array}{l}\text { Rocha \& Silva } \\
(2005)\end{array}$ \\
\hline Mauritia flexuosa L. f. & Buriti & Folha, Fruto, Caule & $\begin{array}{l}\text { Alimentação, Artesanato, } \\
\text { Construção }\end{array}$ & Abaetetuba - PA & $\begin{array}{l}\text { Santos \& Ferreira } \\
(20 \mid 2)\end{array}$ \\
\hline $\begin{array}{l}\text { Orbignya phalerata } \\
\text { Mart. }\end{array}$ & Babaçu & Folha, Fruto, Caule & $\begin{array}{l}\text { Alimentação, Artesanato, } \\
\text { Construção, Combustível, } \\
\text { Medicinal }\end{array}$ & Buíque - PE & $\begin{array}{l}\text { Rufino et al. } \\
(2008)\end{array}$ \\
\hline $\begin{array}{l}\text { Syagrus coronata } \\
\text { (Mart.) Becc }\end{array}$ & Licurí & Folha, Fruto, Caule & $\begin{array}{l}\text { Alimentação, Artesanato, } \\
\text { Construção, Combustível, } \\
\text { Medicinal }\end{array}$ & Buíque - PE & $\begin{array}{l}\text { Rufino et al. } \\
(2008)\end{array}$ \\
\hline
\end{tabular}


Os informantes (82\%) disseram que atualmente existem menos indivíduos de $C$. prunifera quando comparado há tempos pretéritos, sendo as queimadas, desmatamento e $\circ$ avanço das terras agrícolas e pastagens os maiores causadores desse declínio populacional. Drumond (2004) afirma que populações naturais da palmeira licuri [Syagrus coronata (Mart.) Becc. (Arecaceae)], tem sofrido forte degradação, principalmente, por práticas agrícolas inadequadas, exploração indiscriminada da vegetação nativa, queimadas e alta densidade de rebanhos bovinos em áreas da caatinga. Para Reis et al. (20II), atividades como a fruticultura irrigada e a criação de camarões em viveiros (carcinicultura) tem contribuído no processo de degradação dos carnaubais. $O$ mesmo ainda ressalta a importância da produção de mudas de $C$. prunifera e incentivo ao reflorestamento das áreas afetadas.

Todos os entrevistados afirmaram que os produtos derivados da $C$. prunifera apresentam importância na renda local, como extração do pó e artesanato (Figura 2), porém, não possuem equipamentos especializados para a produção da cera. Para Afonso e Ângelo (2009), os habitantes das áreas rurais do Cerrado brasileiro suprem a maior parte de suas necessidades básicas (medicamentos, alimentação, fonte de renda, entre outros) por meio da exploração dos recursos florestais madeireiros e não madeireiros. Do mesmo modo, são diversos os usos dos vegetais pelo homem do campo da região nordeste do Brasil (SILVA et al., 20II; CAMPOS et al., 2015).

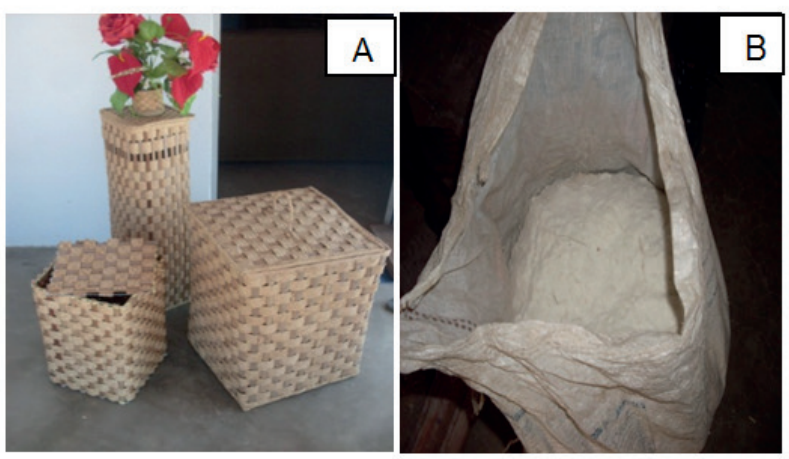

Figura 2 Artesanato (A) e pó da carnaúba (B). Ipanguaçu, Rio Grande do Norte (RN).

Figure 2 Handmade objects (A) and powder of carnauba. Ipanguaçu, Rio Grande do Norte (RN).

Em relação às partes usadas (fruto, folha, raiz, caule), os informantes atribuíram diversos usos, sendo a folha quem mais se destacou ( $45,13 \%$ das citações), com usos na alimentação de bovinos e no artesanato; seguida pelo fruto $(29,09 \%)$, comestível pelo homem; caule
(I2,90\%), usado na construção civil; e raiz (I2,89\%), com uso medicinal. Na Agrovila Picada, as folhas da C. prunifera são utilizadas na produção de artesanato e como alimento para os animais (caprinos, ovinos, bovinos). Os frutos servem de alimento para os animais e humanos. O caule (estipe) é destinado à confecção de ripas e vigas, que são utilizadas em construções residenciais (D'AVILA, 2004; QUEIROGA et al., 20l3). Nascimento (2009), em seu estudo com palmeiras em território krahò (Tocantins - TO), verificou que a maior parte das espécies de palmeiras utilizadas pelos indígenas servem, principalmente, para alimentação, construção e artesanato. Salm et al. (20II), no Distrito Federal, destacam a importância das palmeiras na alimentação, construção e geração de renda para as comunidades locais.

No presente estudo, quando interrogados, todos os informantes afirmaram que sempre deixam parte das folhas na planta, geralmente as folhas mais novas (conhecidas popularmente como mangará) que formam o ápice. Esse método tem grande valor para a conservação da espécie, pois a remoção total das folhas culminaria com a morte do organismo.

O principal produto extraído da C. prunifera é o pó, com o qual é produzida a cera (através de processos industrializados), que está presente na composição de diversos produtos industriais como cosméticos, cápsulas de remédios, componentes eletrônicos, produtos alimentícios, ceras polidoras e revestimentos (MELO et al., 20I2; STOJAKOVIC et al., 20I2).

Segundo informantes, o valor econômico do pó varia de acordo com sua "origem": quando esse produto é extraído de folhas mais velhas o valor é menor ( $5 \mathrm{R} \$ / \mathrm{kg})$, quando comparado com o pó extraído de folhas jovens (7 R $\$ / \mathrm{kg})$. Essa diferença de preço está relacionada com a coloração dos mesmos, pois o pó das folhas velhas apresenta coloração amarelada, enquanto o pó extraído das folhas novas apresenta coloração branca.

De acordo com os moradores, o pó da $C$. prunifera apresentou crescente demanda e aumento de preço nos últimos anos, provavelmente pela grande versatilidade de uso que esse produto possui. Fato semelhante ocorreu na fabricação de artesanato, como vassouras, chapéus e esteiras, sendo a Petrobrás, segundo os entrevistados, uma das principais parceiras na aquisição de esteiras feitas com folhas e pecíolos para o revestimento de dutos de vapor (Figura 3). 


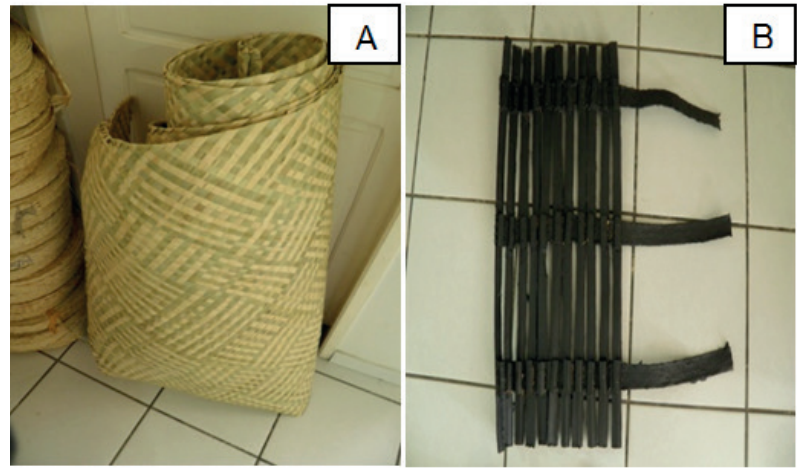

Figura 3 Esteiras de palhas (A) e pecíolos (B) de Copernicia prunifera impermeabilizadas para o revestimento de dutos de vapor da Petrobras. Ipanguaçu, Rio Grande do Norte (RN).

Figure 3 Straw mats $(A)$ and petioles $(B)$ of Copernicia prunifera impermeable for coating duct of gas of Petrobras. Ipanguaçu, Rio Grande do Norte (RN).

Afonso e Ângelo (2009) afirmaram que a exploração de produtos florestais não madeireiros contribui para a criação de empregos e geração de renda nas comunidades, além de ajudar na conservação dos recursos naturais. Apesar de ter sua importância econômica e cultural reconhecida, apenas I8\% dos entrevistados disseram produzir mudas de $C$. prunifera. Mesmo assim, as informações divergiram em relação à germinação, com os seguintes relatos: a) as sementes de $C$. prunifera demoram cerca de um mês para germinarem, b) a germinação pode demorar anos para acontecer e c) as sementes não apresentam dormência. Reis et al. (20I I) observaram maior velocidade de emergência e melhor qualidade de mudas de $C$. prunifera, quando as sementes foram embebidas e cultivadas a pleno sol. Segundo o autor, as sementes emergiram 103 dias após a semeadura.

O conhecimento das populações tradicionais em relação aos recursos naturais que estão inseridos em seu meio é de grande valia para o desenvolvimento de planos de manejo, conservação e sustentabilidade. As informações populares servem de complemento para o conhecimento científico, demonstrando na prática quais as ações são benéficas ou não para o meio ambiente, através da vivência e adaptação as mudanças no ecossistema (CUNHA; ALMEIDA, 2000).

Para Fonseca-Kruel e Peixoto (2004), as pesquisas etnobotânicas possibilitam a obtenção de informações sobre a utilização sustentável da biodiversidade, além de utilizar o saber empírico das comunidades locais.

\section{Grupo de trabalho dos extrativistas e extração do pó da C. prunifera}

A exploração da $C$. prunifera oferece inúmeros riscos de acidentes por se tratar de uma atividade em que o contato com materiais cortantes e perfurantes (foice, espinhos, entre outros) é constante, além da inalação do pó no processo de batição. Foi relatado que nas atividades extrativistas da $C$. prunifera são utilizados poucos equipamentos de segurança individual. Apesar de ser um trabalho com riscos e acidentes registrados (como cortes e perfurações, principalmente), foram citados como constituintes da vestimenta: óculos, chapéu, calça, botas e camisa de manga longa. Entretanto, muitos trabalhadores desprezam o uso de alguns itens de segurança individual, conforme os relatos.

Os trabalhadores exercem funções diferenciadas no processo de extração do pó cerífero da C. prunifera, que se divide em quatro etapas: corte, transporte, secagem e batição (retirada do pó) das folhas (Figura 4). A extração do pó inicia-se com o corte das folhas pelos cortadores, que são os agentes responsáveis pela derrubada das folhas com o auxílio de foice acoplada a uma vara de bambu. As folhas são recolhidas e conduzidas ao local de secagem a pleno sol (área aberta), chamado de estaleiro, utilizando animais de carga (burros ou jumentos) para realizar o transporte. Após a secagem, as folhas são batidas manualmente, para que ocorra o desprendimento do pó, que é, então, recolhido e comercializado.

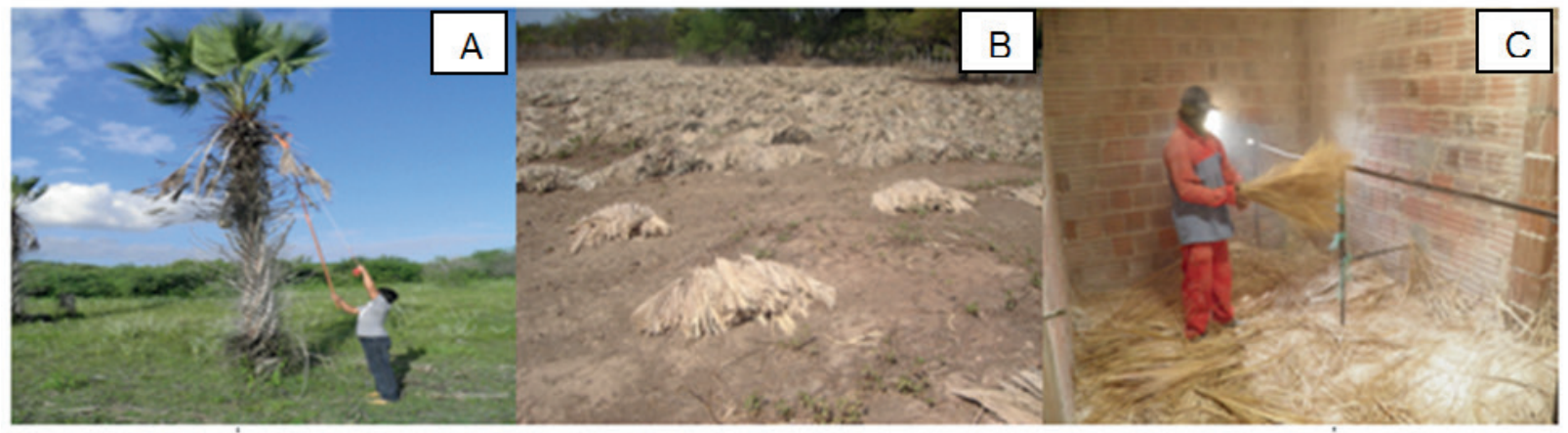

Figura 4 Retirada das folhas (A), secagem (B) e batição das folhas de carnaúba (C). Ipanguaçu, Rio Grande do Norte (RN). Figure 4 Removal of leaves (A), drying (B) and "batição" of leaves of carnaúba (C). Ipanguaçu, Rio Grande do Norte (RN). 


\section{CONCLUSÕES}

\author{
Os informantes da comunidade extrativista \\ avaliada demonstraram possuir importante \\ conhecimento sobre a $C$. prunifera em relação aos \\ aspectos etnoecológicos e etnobotânicos. Considerando \\ que a espécie possui grande importância cultural e \\ econômica para os habitantes da região nordeste do \\ Brasil, os dados apresentados nesse trabalho contêm \\ informações relevantes na elaboração de planos de \\ manejo e conservação da $C$. prunifera. Faz-se necessário \\ uma avaliação aprofundada em outras áreas que \\ abriguem populações dessa espécie, a fim de confirmar a \\ capacidade de resistência e suprimento das necessidades \\ humanas e dos demais animais. \\ Nesse sentido os resultados desta pesquisa irão \\ contribuir para difundir os conhecimentos etnobotânicos \\ e etnoecológicos da $C$. prunifera no semiárido brasileiro. \\ Além disso, permitiu a sistematização das informações e \\ conhecimentos tradicionais, bem como o uso da espécie \\ pelos organismos da região onde se encontra inserida a \\ população estudada.
}

\section{AGRADECIMENTOS}

Ao Conselho Nacional de Desenvolvimento Científico e Tecnológico (CNPq) pelo auxílio financeiro concedido, processo de $n^{\circ}$ 562828/2010-9. À Coordenação de Aperfeiçoamento de Pessoal de Nível Superior (CAPES), pela bolsa de estudo (Mestrado). À colaboração da ONG Carnaúba Viva e aos extrativistas pelo acolhimento.

\section{REFERÊNCIAS}

AFONSO, S. R.; ÂNGELO, H. Mercado dos produtos florestais não-madeireiros do cerrado brasileiro. Ciência Florestal, Santa Maria, v. 19, n. 3, p. 317-328. 2009.

ALBUQUERQUE, U. P. \& ANDRADE, L. H. C. Conhecimento botânico tradicional e conservação em uma área de caatinga no Estado de Pernambuco (Nordeste do Brasil). Acta Botanica Brasílica, São Paulo, v. 16, n. 3, p. 273-285. 2002.

ALBUQUERQUE, U. P.; LUCENA, R. F. P.; ALENCAR, N. L. Métodos e técnicas para a coleta de dados. In: Introdução a Etnobotânica. Recife: Editora NUPEEA, 2010. p. 4I-72.

ARRUDA, G. M. T; CALBO, M. E. R. Efeitos da inundação no crescimento, trocas gasosas e porosidade radicular da carnaúba (Copernicia prunifera (Mill.) H.E. Moore). Acta Botânica Brasileira, São Paulo, Viçosa, v. 18, n. 2, p. 219-224. 2004.
BREWER, D. D. Supplementary interviewing techniques to maximize output in free listing tasks. Field Methods, Washington, v. 14, p. 108-I 18. 2002.

CAMPOS, L. Z. O.; AlbuQUeRQUE, U. P.; PERONI, N.; ARAÚJO, E. L. Do socioeconomic characteristics explain the knowledge and use of native food plants in semiarid environments in Northeastern Brazil? Journal of Arid Environments, v. II5, p. 53-6I, 2015.

CASTANEDA, H.; STEPP, J. R. Ethnoecological Importance Value (EIV) methodology: assessing the cultural importance of ecosystems as sources of useful plants for the Guaymi People of Costa Rica. Ethnobotany Research \& Applications, Cambridge, v. 5, p. 249-257. 2007.

COSTA, C. C. A. Análise comparativa da produção de serapilheira em fragmentos arbóreos e arbustivos em área de caatinga na FLONA de Açu-RN. Revista Árvore, Viçosa, v. 34, n. 2, p. 259-265. 2010.

CUNHA, M. C.; ALMEIDA, M. W. B. Indigenous people, traditional people and conservation in the Amazon. Daedalus, v. I29, n. 2, p. 315-338, 2000.

D'ALVA, O. A. O extrativismo da carnaúba no Ceará. 2004. 194 p. Dissertação (Mestrado em Meio Ambiente e Desenvolvimento) - Universidade Federal do Ceará, Fortaleza.

DRUMOND, M. A. Estratégias de uso sustentável da biodiversidade da caatinga. Brasília: Ministério do Meio Ambiente; UFPE, 2004. p. 329-340.

FONSECA-KRUEL, V. S.; PEIXOTO, A. L. Etnobotânica na Reserva Extrativista Marinha de Arraial do Cabo, RJ, Brasil. Acta Botanica Brasilica, São Paulo, v. I8, n. I, p. I77-190. 2004.

GOMES, J. A. F.; LEITE, E. R.; CAVALCANTE, A. C. R.; CÂNDIDO, M. J. D.; LEMPP, B.; BOMMFIM, M. A. D.; ROGÉRIO, M. C. P. Resíduo agroindustrial da carnaúba como fonte de volumoso para a terminação de ovinos. Pesquisa Agropecuária Brasileira, Brasília, v. 44, n I, p. 58-67. 2009.

HOLANDA, S. J. R.; ARAÚJO, F S.; GALLÃO, M. I.; MEDEIROS FILHO, S. Impacto da salinidade no desenvolvimento e crescimento de mudas de carnaúba (Copernicia prunifera (Miller) H. E. Moore). Revista Brasileira de Engenharia Agrícola e Ambiental, v. 15, n. I, p. 47 - 52, Campina Grande Jan. 201 I.

LINS NETO, E. M. F.; PERONI, N.; ALBUQUERQUE, U.P. Traditional knowledge and management of umbu (Spondias tuberosa, Anacardiaceae): an endemic species from the semi-arid region of Northeastern Brazil. Economic Botany, Bronx, v. 64, n. I, p. II-2I. 2010.

MELO, J. D. D.; CARVALHO, L. F. M.; MEDEIROS, A. M.; SOUTO, C. R. O. PASKOCIMAS, C. A. A biodegradable composite material based on polyhydroxybutyrate (PHB) and carnauba fibers. Composites: Part B, v. 43, n. I, p. 2827-2835. 2012. 
MMA. Secretaria de Recursos Hídricos. Programa de ação nacional de combate à desertificação e mitigação dos efeitos da seca PAN-Brasil. Brasília. 2005. 213p.

NASCIMENTO, A. R. T. Comunidade de palmeiras no território indígena krahò, tocantins, brasil: biodiversidade e aspectos etnobotânicos. Interciencia, Caracas, v.34, n.3, p. $209-219$, mar. 2009.

QUEIROGA, V. P.; RAMOS, G. A.; ASSUNÇÃO, M. V.; ALMEIDA, F. A. C. Carnaubeira: tecnologia de plantio e aproveitamento industrial. Campina Grande: UFCG, 20I3. 204p.

REIS, R. G. E.; PEREIRA, M. S.; GONÇALVES, N. R.; PEREIRA, D. S.; BEZERRA, A. M. E. Emergência e qualidade de mudas de Copernicia prunifera em função da embebição das sementes e sombreamento. Revista Caatinga, Mossoró, v. 24, n. 4, p. 43-49, out.-dez. 201 I.

ROCHA, A. E. S.; SILVA, M. F. F. Aspectos fitossociológicos, florísticos e etnobotânicos das palmeiras (Arecaceae) de floresta secundária no município de Bragança, PA, Brasil. Acta Botânica Brasilica, São Paulo, v. 19, n. 3, p. 657-667. 2005.

RUFINO, M. U. L.; COSTA, J. T. M.; SILVA, V. A.; ANDRADE, L. H. C. Knowledge and use of ouricuri (Syagrus coronata) and babaçu (Orbignya phalerata) in Buíque, Pernambuco State, Brazil. Acta Botanica Brasilica, São Paulo, v. 22, n. I, p. I|4|-I|49. 2008.

SALM, R.; SARDIM, M. A. G.; ALBERNAZ, A. L. K. M. Abundância e diversidade de palmeiras no Distrito Florestal Sustentável da rodovia BR-163, Pará, Brasil. Biota Neotropica, Campinas, v. I I, n. 3, p.99-105. 20 I I.
SANTOS, R. S.; FERREIRA, M. C. Estudo etnobotânico de Mauritia flexuosa L. f. (Arecaceae) em comunidades ribeirinhas do Município de Abaetetuba, Pará, Brasil. Acta Amazonica, Manaus v. 42, n. I, p. I - 10. 2012.

SILVA, F.S.; RAMOS, M. A.; HANAZAKI, N.;ALBUQUERQUE, $U$. P. Dynamics of traditional knowledge of medicinal plants in a rural community in the Brazilian semi-arid region. Revista Brasileira de Farmacognosia, v. 21, p. 382-39I, 201I.

SILVA, L. M.; FISCH, S. T. V. Utilização de palmeiras nativas da Floresta Atlântica pela comunidade do entorno do Parque Estadual da Serra do Mar, Ubatuba, SP. Revista Biociências, Taubaté, v. 18, n. spe, p. 77 - 85. 2012.

STOJAKOVIC, D; BUGARSKI, B; RAJIĆ, N. A kinetic study of the release of vanillin encapsulated in Carnauba wax microcapsules. Journal of Food Engineering, London, v. I09, n. I, p. 640-642. 2012.

TICKTIN, T. The ecological implications of harvesting nontimber forest products. Journal of Applied Ecology, Oxford, v. 4I, n. I, p. II-2I. 2004.

THIOLLENT, M.; SILVA, G.O. Metodologia de pesquisa-ação na área de gestão de problemas ambientais. RECIS, n.I, v. I, p. 93-100. 2007.

WADT, L. H. O.; KAINER, K. A.; GOMES-SILVA, D. A. P. Population structure and nut yield of a Bertholletia excelsa stand in Southwestern Amazonia. Forest Ecology and Management, Amsterdam, v. 21 I, n. I, p. 37I-384. 2005. 